\title{
DEMOCRACIA E DIREITOS HUMANOS: A CRISE DA COVID-19 NO BRASIL COMO MARCO DA RELAÇÃO CONTINGENTE ENTRE OS CONCEITOS
}

\author{
Agenor Cássio Nascimento Correia de Andrade ${ }^{1}$ \\ João Daniel Macedo Sá ${ }^{2}$ \\ Gabriel Santos Lima ${ }^{3}$
}

\section{RESUMO}

O presente aborda o tema da relação conceitual entre democracia e direitos humanos. Para intentar tal abordagem, apresenta-se seus conceitos e a discussão teórica entre eles, optando pela abordagem jurídica das definições. Seguidamente, analisa-se a relação entre os conceitos. Por fim, utiliza-se o caso específico da gestão da pandemia da COVID-19 para ilustrar como exemplo concreto da relação estabelecida. A metodologia do trabalho baseou-se em pesquisa teórica, com levantamento bibliográfico. Para justificar as hipóteses levantadas, foi utilizado o método dedutivo. A conclusão defende que, na contextualização apresentada, a relação entre democracia e direitos humanos termos é contingente ou não necessária.

PALAVRAS-CHAVE: democracia; direitos humanos; crise da democracia no século xxi; direito à saúde; covid-19.

\section{DEMOCRACY AND HUMAN RIGHTS: THE COVID-19 CRISIS IN BRAZIL AS A LANDMARK OF THE CONTINGENT RELATIONSHIP BETWEEN CONCEPTS}

\begin{abstract}
The article is about the conceptual relationship between democracy and human rights. In order to attempt such an approach, its concepts and the theoretical discussion between them are presented, opting for the legal approach to definitions. Next, the relationship between the concepts is analyzed. Finally, the specific case of the management of the COVID-19 pandemic is used to illustrate as a concrete example of the established relationship. The work methodology was based on theoretical research, with a bibliographic survey. To justify the raised hypotheses, the deductive method was used. The conclusion argues that, in the context presented, the relationship between democracy and human rights terms is contingent or not necessary.

\footnotetext{
${ }^{1}$ Mestrando em Direito na Universidade Federal do Pará (UFPA), na área temática "Normas Fundamentais Processuais e Processo Coletivo/Técnicas de Coletivização". Especialista em Direito Público pela Universidade Católica de Petrópolis. Juiz de Direito do Tribunal de Justiça do Estado do Pará (TJPA). Constelador Sistêmico. Facilitador de Círculos Restaurativos. Formador da Escola Nacional de Formação e Aperfeiçoamento dos Magistrados (ENFAM). Professor Visitante da Escola Judicial do TJPA "Hélder Lisboa". E-mail: agenordandrade@gmail.com.

${ }^{2}$ Doutor em Direito pela Universidade Federal do Pará. Advogado. Professor adjunto da UFPA. É membro do corpo docente permanente do Programa de Pós-Graduação em Direito da UFPA e membro da Comissão de Meio Ambiente da OAB/PA. Coordenador do Grupo de Pesquisa Teoria do Direito, Meio Ambiente e Justiça (http://dgp.cnpq.br/dgp/espelhogrupo/228885). Contato: joaosa@ufpa.br.

${ }^{3}$ Mestrando em Direito pelo Programa de Pós-Graduação em Direito da Universidade Federal do Pará (PPGD/UFPA). Graduado em Direito pela Universidade Federal do Pará, com período de mobilidade acadêmica internacional na Faculdade de Direito da Universidade de Lisboa (ULisboa). Membro do Grupo de Pesquisa Teoria do Direito, Meio Ambiente e Justiça (http://dgp.cnpq.br/dgp/espelhogrupo/228885). Contato: gabrielsantoslima@live.com.
} 
KEY-WORDS: democracy; human rights; crisis of democracy in the 21st century; right to health; covid-19.

\section{INTRODUÇÃO}

A democracia e os direitos humanos são conceitos que encontram previsão expressa no texto constitucional brasileiro (art. 1' , "caput", e art. $4^{\circ}$, II da Constituição de 1988), sendo na seara jurídica termos grandemente difundidos e que parecem ter implicações entre si. $\mathrm{Na}$ sociedade em que vivemos, é quase incompreensível não defender a bandeira da democracia e dos direitos humanos.

Ainda que sejam noções importantes, tem se discutido na literatura especializada (MOREIRA, 2020) o que se chama de crise na democracia no século XXI, um movimento que traz diversas implicações e decorrências que se fazem sentir nos diversos campos políticos, sociais e econômicos. Destaca-se, ainda, que nessa literatura o Brasil se apresenta como um case de (in)sucesso dos sintomas e causas do fenômeno. Ao mesmo tempo, diversos indicadores internacionais buscam medir a "qualidade" dos regimes democráticos pelo mundo e indicadores sociais e políticos das ditas novas democracias, além de acontecimentos eleitorais controversos e uma forte contestação na considerada maior democracia do mundo em 2020, os EUA.

Assim, a pandemia veio acentuar a crise democrática especialmente nos países que já vinham enfrentando algumas instabilidades institucionais, como o Brasil, em razão do embate social, do esgotamento da estrutura que não atingiu apenas o setor público, mas também de forma intensa o setor privado, aumento de preços e desemprego, aliado a movimentos antidemocráticos e contra a ciência, sustentado principalmente pelos discursos e práticas negacionistas do próprio governo federal. A sociedade brasileira, que já vinha de um padrão de polarização política e social, experimentou grave crise que afetou inclusive a relação institucional entre os três Poderes, diante das investidas do Presidente da República para impor uma retórica que pudesse colocar em xeque a credibilidade e a solidez dessas instituições, o que fez com que, em um momento de forte crise, os eleitores que se aliavam ao seu discurso, seguissem e depositassem sua confiança no chefe do executivo e criasse movimentos como o antivacina, movimento pró fechamento do STF ou contrários às políticas 
adotadas por governadores e prefeitos para combater a covid-19, como o lockdown e o isolamento social.

Esses movimentos demonstram a importância de discutir conceitualmente alguns dos termos que se desenvolvem nesse contexto. Por outro lado, a definição dos termos é controversa e nos traz a necessidade de dar um passo atrás em face da pluralidade das teorias democráticas, cujo refino teórico cada vez mais se encontra nas condições de concretização de direitos fundamentais. Ao mesmo tempo, a crise democrática no Brasil parece andar de mãos dadas com a violação de direitos humanos promovida em larga escala por governos que tensionam a democracia. Essa relação se fez notória pelo contexto de atuação do Governo Federal no âmbito da gestão da pandemia de Covid-19 nos anos de 2020 e 2021.

Dessa forma, reside o questionamento da relação conceitual entre democracia e direitos humanos, a fim de aferir se a atual contestação das instituições democráticas no Brasil se constitui como um ambiente para a violação dos direitos humanos, no qual a negação do direito à saúde, no contexto pandêmico no país, seria um sintoma dessa crise.

$\mathrm{O}$ problema de pesquisa se traduz pelo seguinte questionamento: em que medida se estabelece a relação entre a crise democrática do século XXI e a violação do direito humano à saúde no Brasil na conjuntura temporal da pandemia do novo Coronavírus?

O objetivo geral da pesquisa é analisar em que medida é estabelecida a relação da crise democrática e o contexto de violação do direito humano à saúde no Brasil em relação à gestão da pandemia do novo Coronavírus.

Os objetivos específicos são: contextualizar democracia e direitos humanos em uma acepção jurídica; identificar a relação teórica entre democracia e direitos humanos, e; analisar a repercussão da relação estabelecida em relação à crise democrática e gestão da pandemia no Brasil.

Para responder ao problema levantado, a metodologia do trabalho será dedutiva, uma vez que utilizaremos de premissas gerais de correntes teóricas dos direitos humanos e democracia, a partir das quais se fará análise da aplicação dos conceitos numa conjuntura temporal e espacial específica, a gestão da crise do novo Coronavírus no Brasil. O presente artigo utilizou as os tipos de pesquisa bibliográfica e documental. A pesquisa bibliográfica se desenvolveu através do desdobramento dos objetivos em uma parte mais teórica e outra mais prática. A conceituação dos principais termos do problema foi fundamental para o 
estabelecimento, conforme o estado da arte, de uma linha coerente de autores para o recorte específico pretendido.

O questionamento partiu da hipótese de que haveria uma relação necessária entre os conceitos de democracia e direitos humanos, ou seja, que ao se pensar em democracia, intuitivamente, pensar-se-ia em direitos humanos e vice-versa, fazendo com que houvesse um desenvolvimento de forma dependente dos dois conceitos. Ao final, conforme será demonstrado ao longo do trabalho, defendemos que, na verdade, essa relação entre os conceitos não é necessária.

Estruturalmente, dividimos este texto da seguinte maneira: na primeira seção, apresentamos uma discussão dos conceitos de democracia e direitos humanos; na segunda seção, elaboramos uma base para relacionar os dois conceitos; e por fim, faremos uma breve análise sobre a violação do direito humano à saúde no contexto da pandemia da Covid-19 no Brasil dentro da crise democrática na gestão de Jair Bolsonaro à frente do Governo Federal.

\section{COMPREENSÃO E CONCEITOS INICIAIS DE DEMOCRACIA E DIREITOS HUMANOS}

Para o correto dimensionamento do que se pretende no presente trabalho, faz-se necessário, antes da relação estabelecida, compreender o debate atual entre as definições de democracia e direitos humanos. Ocorre que os dois termos passam, se não por incompreensões, por pontos de vistas distintos que podem inviabilizar o debate. Dessa forma, faremos um recorte específico para que as análises sobre os termos caibam na discussão atual que se desenvolve no Brasil, especialmente diante do impasse entre crise democrática e crise dos direitos humanos na atuação do Governo na pandemia da Covid-19.

Em certa medida, o conceito de democracia acabou no contexto liberal estando associado principalmente à ideia de uma competição eleitoral (MOREIRA, 2020). Essa ideia nos levou à noção parcial de que se tenho eleições relativamente justas e periódicas em determinado espaço de tempo, tenho uma democracia consolidada. A medida da democracia seria aferida, portanto, na contagem entre quantos anos sem um golpe de Estado estabelecido.

No entanto, Streeck (2012, p. 102) trazendo o exemplo do contexto europeu, expõe que há uma redução contínua da participação dos cidadãos nas eleições democráticas, sobretudo das classes menos favorecidas. O autor traz como registro que a queda na 
participação eleitoral é maior nas regiões com maior taxa de desemprego e de beneficiários de assistência social.

Assim, a partir da visão de Streeck, pode-se concluir que democracia e participação eleitoral não possuem uma relação simbiótica ou sinonímica, e que o aumento de eleitores não reflete na mesma proporção na concretização da democracia. Os dados demonstraram que houve diminuição da participação eleitoral nas democracias capitalistas, pois as eleições teriam sido desacreditadas e não se via mais uma mudança social com um novo partido no governo, ou seja, as eleições deixaram de fazer diferença.

Essa divergência tem relação específica às condições materiais para exercício de direitos políticos, em face das desigualdades sociais e ausência de desenvolvimento material mínimo, o que se mostrou um profundo gargalo na teoria liberal, e, por consequência, no grande destaque das teorias mais sofisticadas do que seria democracia. Dessa forma, a noção exclusiva de uma democracia eleitoral, ou de uma suposta organização, não é garantia efetiva de democracia, que se trata de uma definição plúrima, especialmente preocupada com a efetividade das condições reais de existência.

Não obstante a essa visão, em face de uma sistemática violação de direitos, sobretudo no sul global, especialmente em direitos sociais, o princípio democrático foi repercutido a partir de uma não concretização de, inclusive, direitos mais caros aos liberais.

Diante da dificuldade real de conceituar democracia, encontramos em ca Em nossa visão, portanto, os diferentes níveis poliárquicos podem ser uma razão forte para considerar as violações sistemáticas de direitos humanos dentro de um Estado nacional, nos moldes do que propomos na última seção, e podem ser associados a violações sistemáticas de governos.

Por sua vez, a noção de direitos humanos é igualmente relevante e se desenvolveu sobretudo no pós-guerra, momento chave para sua afirmação histórica. No entanto, conquanto seja um termo definitivamente apropriado pela comunidade política e jurídica ocidental, em relação à sua natureza paira um grande desacordo teórico. E essa definição se notabilizou principalmente pela dualidade entre concepções ortodoxas e políticas.

De um lado, as concepções ortodoxas nos dizem que os direitos humanos são provenientes de uma moral decorrente da própria natureza humana do indivíduo, enquanto as concepções políticas nos dizem que a essência dos direitos humanos é moldada a partir de suas funções no âmbito de uma prática internacional (TRIVISONNO; RODRIGUES, 2018). 
A concepção ortodoxa nos traz uma visão mais jurídica do termo, ainda que relacionada a um direito natural, em que preponderam a tese da universalidade e a tese da razão humana, cujas bases se encontram no iluminismo (TRIVISONNO; RODRIGUES, 2018). Ainda que dialoguem sobre as mesmas bases, há um desacordo teórico entre os autores do mesmo campo sobre o que seria essa universalidade, e a própria noção e catálogo de direitos. Resta-nos perguntar se a democracia estaria relacionada.

A concepção política, por sua vez, demonstra um raciocínio mais condizente com a prática dos sistemas internacionais de direitos humanos, vez que estamos diante de uma perspectiva essencialmente pautada em uma prática discursiva internacional, em moldes quase hartianos (TRIVISONNO; RODRIGUES, 2018). O fato é que é uma abordagem típica da filosofia analítica, que se baseia numa ordem internacional cujas bases poderiam ser questionadas pela comunidade internacional. Não menos polêmico ante os limites de soberania e o próprio catálogo de direitos partilhados nessa comunidade política.

Fato é que paira profundo desacordo teórico entre o conceito até mesmo pela diversidade de aplicação e abordagem. Caso se esteja falando de sistema internacional, por exemplo, parece mais correto na compreensão de uma prática discursiva. Por outro lado, se temos a incorporação ou mesmo a compreensão de direitos a partir de um texto constitucional, que não raras vezes são desenvolvidas como a questão ambiental, social ou individual no âmbito de legislações como a brasileira, teríamos a priori uma noção mais ortodoxa de direitos humanos.

Em resumo, o entendimento sobre cada termo não é pacificado, mas se utilizarmos a versão de democracia de O'Donnell e as concepções ortodoxas de direitos humanos, que partem da ideia de direitos jurídicos, é possível criar uma associação entre os termos. Essa relação podemos discutir a partir do contexto das crises democráticas do século XXI, que se fazem sentir ao menos no caso específico que desenvolveremos melhor na terceira parte.

\section{RELAÇÃO ENTRE DEMOCRACIA E DIREITOS HUMANOS NA ACEPÇÃO JURÍDICA}

Dados os conceitos, resta-nos estabelecer em que momento e qual a relação podemos estabelecer entre os dois termos. É nesse sentido que nos parece que a relação é direta, mas ao mesmo tempo contingente, dependendo dos termos em que estamos falando. Dessa forma, 
partimos do pressuposto da concretização de direitos humanos e democracia especificamente dentro de uma comunidade jurídica específica, ou seja, na compreensão em termos ortodoxos e por meio da concepção de democracia a partir de direitos formais. Nessa vertente, temos duas relações possíveis, uma ligada ao conceito de direito e outra relacionada à concepção de democracia em si.

Ainda que sejamos levados intuitivamente a uma ligação automática entre os termos, veremos que, no que tange à base conceitual, os dois termos bebem de fontes diferentes. $\mathrm{O}$ primeiro ponto se desenvolve no âmbito das teorias do direito. A teoria preponderante entre as teorias do direito atualmente é o positivismo jurídico, em que autores liberais conduziram acordos teóricos para descrição ou prescrição do que "é o direito". Seja uma compreensão baseada num acordo linguístico, ou ciência do direito ou até mesmo numa concepção interpretativa, todas as teorias são respaldadas por um sentido liberal e uma democracia liberal. Os maiores autores desenvolvem suas teorias do direito na perspectiva que a democracia é uma relação anterior e necessária.

No entanto, em nenhuma dessas concepções, embora tenham se desenvolvido no pósguerra, fazem referências explícitas aos direitos humanos da forma como é colocada juridicamente. Os conceitos são mais apropriados em círculos diferentes de abordagem. $\mathrm{O}$ positivismo exige um regime democrático, que não parece, a primeiro momento, ter relação, ao menos direta, com os direitos humanos. Isso porque o positivismo não esboça uma relação conceitual com os direitos humanos, que se traduz pela própria dificuldade de estabelecer uma justificação conceitual de uma ordem de direito internacional em si.

A nossa hipótese é a de que, na perspectiva jurídica, a relação entre democracia e direitos humanos, da maneira que contextualizamos, é uma relação contingente. Ao falar da inflexão entre democracia e direitos humanos, é mais pertinente encararmos, em primeiro lugar, uma dimensão propriamente jurídica do termo, uma vez que se está falando de incluirmos direitos na essência jurídicos ao ordenamento político de um estado.

Ainda numa perspectiva jurídica, que nos fará essencialmente refletir de maneira aprofundada no terceiro tópico, temos que essa tensão pode ter relação com a dualidade de termos entre uma ideia de democracia liberal e de liberal antidemocrático. Essa reflexão estaria condicionada especificamente e evidenciada nos termos do contexto da crise das democracias no século XXI. Nesse sentido, o fundamento de um sistema liberal antidemocrático seria em decorrência de um sintoma/causa do referido fenômeno no sentido 
de respeitar garantias individuais e independência entre os poderes, mas as decisões políticas contrariam a vontade popular em detrimento da vontade de grandes corporações, em que o exemplo maior seria o caso da Grécia diante do não atendimento do plebiscito realizado em 2015, cedendo à pressão do FMI e do Banco Central Europeu (MOREIRA, 2019).

Por sua vez, a democracia iliberal seria um sistema em que, independentemente de respeitar a vontade popular, as garantias constitucionais seriam desrespeitadas em essência, cujo exemplo seria o plebiscito na Suíça em 2009 que, através de um plebiscito, impediu a construção de um minarete em um pequeno vilarejo (MOREIRA, 2020). Ou seja, uma pauta minoritária, contra a manifestação religiosa de um grupo não dominante, foi impedida pela população. Outro exemplo emblemático é o governo de Viktor Orbán na Hungria, o qual é acusado de violações sistemáticas, além de influenciar na composição de ministros, o que afronta o sentido dos valores liberais em sua essência. Não obstante a isso, o governo foi reeleito seguidas vezes e conta com massivo apoio popular.

Assim, a essência da democracia iliberal seria um sistema no qual as escolhas democráticas são cooptadas por uma pauta contrária não só às noções mais liberais, mas substancialmente às pautas antipovo e antiminorias. Dessa forma, a concretização de uma democracia eleitoral poderia estar associada, em alguma medida, a um ambiente propício para solapar direitos humanos.

Outro ponto importante a ser analisado é a influência das desigualdades categóricas sobre a democracia e como esse fenômeno impacta os direitos humanos. O autor Chales Tilly (2013), em seu livro "Democracia", no capítulo referente à Igualdade e Desigualdade, analisa a influência das desigualdades categóricas sobre a democracia.

Sua compreensão é de que a desigualdade dificulta o processo de democratização. Para o autor, a desigualdade social impede a democratização e mina a democracia, na medida em que solidifica diferenças contínuas e diferenças categóricas cotidianas, o que acaba afetando os processos políticos públicos, quando são disponibilizadas quantidades de recursos desproporcionais entre os grupos políticos. Nesse específico ponto é que as desigualdades categóricas afetam diretamente a democracia.

A persistência da desigualdade categórica, com a reprodução das circunstâncias que facilitam a exploração e o acúmulo de oportunidades pelos membros mais favorecidos, ocasiona sérios obstáculos na concretização da democracia, porque causam danos aos excluídos, privando-os de acesso a bens que deveriam ser coletivos e porque os meios 
coercitivos estão na base de alguns sistemas de desigualdade e servem para manutenção do mesmo status quo de desigualdade.

Portanto, nota-se que a prevalência de recursos geradores de desigualdades afeta totalmente um governo democrático. Os regimes que se baseiam sobre o controle da terra, do trabalho e dos meios produtivos são muito mais propícios à tirania.

Essa disparidade distributiva afeta sobremaneira a democracia, pois gera instabilidade que prejudica o funcionamento desse tipo de regime. Por isso, as economias capitalistas abrigam regimes democráticos com mais frequência que outros tipos de sistema. $\mathrm{O}$ capitalismo financeiro e industrial plenamente desenvolvido propicia a existência de governos que não necessitam para sua sobrevivência a reprodução das desigualdades categóricas da vida cotidiana, haja vista que se demonstrou que é muito melhor para a economia capitalista manter um equilíbrio entre a massa de consumidores e a massa de cidadãos.

Nesse sentido, o aumento das desigualdades categóricas sem um ajuste compensatório provoca ameaça à democracia. A superação desse quadro se daria com a equalização material entre as categorias com a proteção dos processos políticos das desigualdades, pois a consolidação da democracia implica em queda das desigualdades, já que a democracia não se fortalece na presença de extrema desigualdade.

A partir desse contexto, a relação entre a democracia e direitos humanos pode ser analisada no Brasil especialmente no contexto de uma tensão na democracia por parte do Governo, bem como pela difusão de indicadores e relatórios sobre direitos humanos com a problemática gestão da crise pandêmica.

Nesse sentido, se a relação entre democracia e direitos humanos, numa projeção teórica da teoria do direito dominante não é necessária, numa perspectiva política podemos associar de alguma forma a crise democrática com a crise de direitos humanos, especialmente no direito humano à saúde, a qual pode ser amplificada no âmbito das teorias políticas mais recentes.

\section{CRISE DA DEMOCRACIA BRASILEIRA E A CRISE DOS DIREITOS HUMANOS A PARTIR DA GESTÃo dA PANDEMIA DE COVID-19 NO BRASIL}

Apesar da projeção teórica aqui adotada indicar uma relação não necessária entre democracia e direitos humanos, parece-nos inequívoco que os dois termos podem se 
influenciar mutuamente, sobretudo no contexto do que se entende por crise das democracias no século XXI.

Nesse sentido, vale lembrar o conceito de pêndulo da democracia, trazido por Avritzer (2019, p. 16), significando a percepção de um movimento alternado de forças antidemocráticas em determinadas conjunturas, em que há a oscilação política nos quais as elites e massam partilham de um forte entusiasmo democrático e outros momentos em que a classe média adota uma visão antidemocrática, alinhada com as elites, e muitos setores populares aderem à rejeição da política ou à antipolítica.

É nessa linha que caminhamos para estabelecer essa relação, especialmente no que concerne à gestão da pandemia da COVID-19 pelo governo brasileiro, que se materializa tanto uma crise democrática, quanto uma crise dos indicadores de direitos humanos, com ênfase na violação do direito à vida de grupos mais vulnerabilizados.

A análise do que pretendemos expor perpassa, em primeiro lugar, pela visualização da plataforma eleitoral do governo eleito democraticamente em 2018 com quase 58 milhões de votos. No documento, obrigatório pela legislação eleitoral (embora não vinculante para efeitos de cumprimento), consta o "redirecionamento da política de direitos humanos, priorizando a defesa das vítimas da violência" (BRASIL, 2018). Essa é a única citação ao termo direitos humanos pela então candidatura que acabou vencedora do pleito presidencial. Embora pareça um padecimento às vítimas, a mesma seção esboça uma defesa da diminuição da maioridade penal para crianças e adolescentes, bem como o recrudescimento da atuação policial.

Os problemas verificados na plataforma (e campanha) culminaram posteriormente numa atuação prática do governo em tentar governar de forma unilateral, com larga utilização de decretos, no intuito de reverter principalmente políticas públicas contra grupos minoritários, conforme Vieira e Glezer (2019), assim como o aparato institucional da Presidência da República foi utilizado para atacar outros Poderes, adversários políticos, imprensa e desarticular a salvaguarda de direitos fundamentais. O Governo Federal, portanto, encabeçou de modo concomitante uma crise política, democrática e de direitos humanos. Mais do que isso, os movimentos governistas nos fazem refletir no âmbito da democracia tanto uma possível ressonância de um movimento político assentado nas urnas, quanto no sentido de uma violação sistemática em lugares não poliárquicos da poliarquia.

No entanto, o eleitor faltoso ou contrário ao governo não pode jamais ser excluído dos benefícios de políticas públicas, pois é parte integral da comunidade e possui os mesmos 
direitos que os demais. O Governo não pode ter iniciativas que beneficie um grupo em detrimento de outros, excluindo os que não votaram em seu partido (SANTOS, 2017, p. 118).

Num primeiro contexto, a crise brasileira está materializada pelo que expõe Moreira (2019) na conceituação de uma democracia iliberal, a qual seria uma forma de governo chancelado pelas supostas vias democráticas que propugna ideias contrárias as plurais noções de democracia, impactando inclusive numa chancela da maioria contra direitos das minorias. Essa noção está, pelo que foi discutido anteriormente, em plena consonância com o sentido de democracia eleitoral. Essa primeira versão, apesar de haver uma consonância de agenda eleita democraticamente, contrasta com a noção de poliarquia substancialmente por dificultar o acesso a direitos básicos por via de mecanismos estruturais, bem como o acesso efetivo de direitos formais pelas minorias políticas.

Por outro lado, não obstante o Governo Bolsonaro tenha sido eleito pelo voto em urna eletrônica, propugna a ideia errônea de não confiabilidade nesse instrumento de votação principalmente como pauta discursiva para manter a base aliada. O governo Bolsonaro se materializou também pela inflamação da sociedade contra as pautas democráticas, apregoando o descrédito das urnas que os elegeram, bem como inflamando populares a manifestações contra o sistema eleitoral. Contraditoriamente, nesses termos, o Governo age como negação da própria democracia eleitoral que o elegeu, contrastando portanto contra mais uma concepção de democracia.

Em terceiro lugar, a crise democrática se faz sentir pelo jogo duro, aos moldes do que propõe Tushnet (2003), encenado frente a outros Poderes e Unidades da Federação. Dessa forma, uma agenda sistemática, contando inclusive como grupos conservadores para inflamar as instituições. Fruto dessa disputa tivemos uma gestão desastrosa e desarticulada da pandemia, que culminou inclusive na judicialização frente ao STF das medidas sanitárias de combate ao novo Coronavírus, resultante do conflito federativo entre Governadores e Prefeitos contra a Presidência da República (SILVA; BAHIA, 2020).

Basta notar o grande número de ações, no contexto da covid-19, e a atuação do Poder Judiciário acerca de distribuição de medicamentos, regulação sobre o funcionamento de estabelecimentos, vagas de leito em uti, entre outros.

As ações de descumprimentos de preceito fundamental $n^{\circ} 709$ e $n^{\circ} 742$, que contestaram no Supremo Tribunal Federal a existência de plano nacional de enfrentamento aos grupos vulneráveis indígenas e quilombolas, respectivamente, são outro exemplo da 
ineficácia do combate à pandemia pelo governo federal, na medida em que apontavam vários atos comissivos e omissivos violadores de seus direitos e o Judiciário, embora não tendo legitimidade democrática para determinar a criação de políticas públicas, foi exortado a atuar considerando o período de crise como é o caso do atual cenário de calamidade pública enfrentado pelo Estado brasileiro em virtude da pandemia ocasionada pela Covid-19. Nota-se que, diante de situações de latente violação de direitos humanos por parte do Poder Executivo federal, os princípios da Constituição e do Estado Social e Democrático de Direito deveriam ser garantidos.

A ADPF 709, impetrada pela Articulação dos Povos Indígenas do Brasil (APIB), juntamente com outros seis partidos políticos, exigia o equacionamento de graves lesões a preceitos fundamentais desta Constituição, relacionadas às falhas e omissões no combate à epidemia do novo coronavírus entre os povos indígenas brasileiros. A União não estaria levando em consideração que os danos e riscos para os povos indígenas são ainda maiores do que para o restante da população, em razão da possibilidade de extermínio de etnias, principalmente de grupos isolados ou de recente contato.

A ADPF relatou ainda vários pontos que comprovavam a irresponsabilidade sanitária da União na proteção da causa indígena, entre os quais: 1) a não contenção de invasões à terras indígenas ou a não remoção de seus invasores, forçando contato com as tribos; 2) ações equivocadas do governo federal em matéria de saúde, com o ingresso, em terras indígenas, de equipes de saúde sem cumprimento de quarentena e sem a observação de medidas de prevenção ao contágio; 3) decisão política da Fundação Nacional do Índio (Funai) e da Secretaria Especial de Saúde Indígena (Sesai) de só prestar assistência especializada de saúde a povos residentes em terras indígenas homologadas, remetendo-se os indígenas não aldeados (urbanos) ao SUS geral (sem expertise para trato de indígenas) e, aparentemente, deixando as demais tribos, que residem em terras indígenas pendentes de homologação, sem atendimento; e 4) não elaboração de um plano pormenorizado e concreto, que contenha uma estratégia de proteção das comunidades indígenas e um cronograma de implementação, com a participação das comunidades indígenas.

$\mathrm{Na} \operatorname{ADPF} 742$, que trata da questão quilombola, não foi diferente. Foi ajuizada pela Coordenação Nacional de Articulação das Comunidades Negras Rurais Quilombolas CONAQ, em conjunto com os partidos PSB, PSOL, PCdoB, REDE e PT, requerendo que o Supremo Tribunal Federal determinasse, dentre outras medidas, a elaboração e 
implementação de um "Plano Nacional de Combate aos Efeitos da Pandemia de Covid-19 nas Comunidades Quilombolas", semelhante ao determinado pela Corte na ADPF 709 para a proteção das populações indígenas.

Nela, reconheceu-se o direito à implementação de medidas específicas para combate à COVID diante da vulnerabilidade social das comunidades, agravada pela pandemia. O pedido na ação constitucional foi além da inclusão dos quilombolas na vacinação prioritária, foram requeridas medidas como a disponibilização de materiais de higiene, promoção de testagens, logística para acesso a leitos hospitalares, além da garantia do acesso à alimentação e água potável, para se demonstrar o amplo e especial cenário de vulnerabilidade.

$\mathrm{Na}$ ação, demonstrou-se a precariedade do sistema de atenção à saúde nos municípios onde estão presentes as comunidades quilombolas, com condições péssimas de saneamento e a maior incidência, na população negra, de doenças que representam comorbidades à Covid19.

Nos dois casos demonstrados (indígenas e quilombolas), pode-se notar que a postura irresponsável no tratamento da pandemia pelo governo federal se somou ao posicionamento discriminatório assumido pelo Presidente da República contra a população indígena e quilombola, principalmente no que concerne à demarcação de suas terras. São comunidades de extrema vulnerabilidade e alto risco, mas que não estavam tendo qualquer ação específica de enfrentamento da pandemia.

A nossa hipótese é a de que a crise democrática no Brasil, e ela se manifesta aqui em vários sentidos no que discorremos, agrava o fundamento de muitos direitos humanos concretizados no ordenamento brasileiro. Essa manifestação em relação ao direito à saúde, que foi vulnerabilizado em face da gestão (ou falta dela) da pandemia em decorrência de uma plataforma intencional, exemplificado até mesmo na constante troca de ministros de saúde durante o início da pandemia (três ministros) e, no considerado ápice, com a posse do quarto ministro em março de 2021.

Por sua vez, o fenômeno especialmente associado à crise do coronavírus encontra ressonância específica por uma prática proposital de imunidade de rebanho e a apropriação de uma pauta ideológica por parte do Governo brasileiro, que teve um impacto negativo nos direitos humanos, confirmado com a morte de mais meio milhão de pessoas (VENTURA; BUENO, 2021). Mortes que poderiam ter sido evitadas se o governo federal brasileiro tivesse 
gerido a crise de saúde e sanitária a partir de evidências científicas e seguindo recomendações de organizações internacionais, sobretudo da Organização Mundial da Saúde.

Nesse sentido, é bom ressaltar que apesar da prática discursiva de atuação do Presidente e seus auxiliares, o falso dilema entre economia e preservação da saúde, com medidas de proteção ao coronavírus, e que uma gestão eficiente da pandemia, através dos mecanismos recomendados pelas autoridades sanitárias, é essencial não só para salvaguardar o direito humano à saúde, como outros decorrentes, bem como o efeito socioeconômico (BOHOSLAVSKY, 2021)

Por sua vez, a vulneração do direito à saúde é relatada pela anistia internacional, enfatizando que o Governo não promoveu adequadamente a disponibilização a serviços básicos de saúde e devido resguardo social à população, agravando o grave quadro socioeconômico, dentre outros motivos "pelas constantes tensões entre autoridades federais e estaduais, pela ausência de um plano de ação claro e baseado nas melhores informações científicas disponíveis" (ANISTIA INTERNACIONAL, 2021, p. 64). Cabe ressaltar ainda que "políticas públicas e medidas ineficazes para amenizar o impacto da Covid-19 entre as comunidades tradicionais ressaltaram o fracasso do Estado em garantir o direito à saúde desses grupos" (ANISTIA INTERNACIONAL, 2021, p. 67).

$\mathrm{Na}$ perspectiva do que propomos a vulneração desses direitos notoriamente humanos, na acepção jurídica do termo, é fruto de uma concepção contraditória da crise democrática. Nesse sentido, a relação é diretamente proporcional em relação à crise democrática no contexto brasileiro e a gestão do direito humano à saúde, cujo impacto negativo se manifesta especialmente em grupos vulneráveis. Dessa forma, a crise da democracia no Brasil parece ter uma relação com a violação dos direitos humanos no contexto da pandemia.

\section{CONSIDERAÇÕES FINAIS}

Com base no exposto, tentamos indicar de maneira provisória a relação entre democracia e direitos humanos no contexto da crise democrática recente que assola o Brasil, especialmente no sentido de enquadrá-la como relação necessária. Para tanto, foi importante compreender principalmente as concepções jurídicas dos dois termos.

Na seção inicial foi possível desenvolver uma abordagem alternativa de democracia, e especialmente, de crise da democracia do século XXI, no sentido de especificar os rumos 
pertinentes para nossa empreitada. Para consecução de tal, foi preciso adentrar na análise da literatura especializada trazida por Moreira (2020), bem como na reflexão crítica das concepções democráticas por Streeck (2018), para quem a crise democrática contrasta com os limites epistêmicos do próprio conceito majoritário de democracia liberal.

Nesse sentido, o conceito de poliarquia, na abordagem trazida, pode ser um caminho possível, tendo em vista a atenuação conceitual em relação à dificuldade teórica do termo democracia. Ao mesmo tempo, permite uma preocupação com as condições materiais e o enquadramento de direitos formais vinculado a um mínimo de equidade material. Dessa forma, é um conceito político e jurídico que pode nos ser útil para estabelecer a relação entre democracia e direitos humanos.

Por sua vez, também foi possível compreender o desacordo teórico que envolve o termo direitos humanos. Sob o termo, pairam diversas concepções, políticas, jurídicas e morais. Dependendo do que se pretende, podemos ter uma ou outra dimensão aplicável. Ainda que importante, o contexto das práticas e dos sistemas regionais e universais de direitos humanos não nos toca diretamente o objeto do presente trabalho. Por outro lado, a nossa defesa foi no sentido de adotar as teorias ortodoxas com a finaldiade de unicamente compreender os direitos humanos numa perspectiva até mesmo moral que integra os ordenamentos jurídicos.

Diante disso, vimos que a relação estabelecida é uma relação não necessária entre democracia e direitos humanos, embora seja possível visualizar uma influência recíproca quando se fala de crise democrática e crise de direitos humanos. A contingência da relação está dada pela ausência de vínculos e a própria concepção jurídica contraditória e plural entre os dois termos. Por outro lado, contrasta com o próprio desenvolvimento dos dois termos. Nesse contexto, no recorte traçado por nós, o enlace teórico entre as duas definições é uma relação que embora quista, não é necessária. E isso se pode ver desde as concepções teóricas do direito dominantes até hoje.

Para testar essa relação, utilizamos a crise democrática no Brasil no contexto da pandemia do novo Coronavírus, o que nos permitiu evidenciar melhor essa relação. Nesse contexto, é perceptível o enquadramento do cenário brasileiro no que se entende por crise democrática do século XXI. Assim, é especialmente relevante que se contextualize o próprio cenário de um governo que, embora com pautas notadamente antidemocráticas e avessa a uma defesa efetiva dos direitos humanos transparente, foi eleito democraticamente (democracia 
eleitoral) e ainda conta com expressiva adesão de uma parcela da população. Ao mesmo tempo, pela literatura especializada, relaciona-se o mesmo governo como o responsável por uma conduta notadamente contrária aos direitos humanos de maneira explícita e proposital. Nesse aspecto, encaminhamos a presente pesquisa no sentido de que a relação no contexto da gestão da pandemia do novo Coronavírus no Brasil evidencia essa relação contingente entre democracia e direitos humanos.

\section{REFERÊNCIAS BIBLIOGRÁFICAS}

ANISTIA INTERNACIONAL. Informe 2020/21: o estado de direitos humanos no mundo. Londres, Reino Unido: Amnesty International, 2021. Disponível em: <https://www.amnesty.org/download/Documents/POL1032022021BRAZILIAN\%20POR T UGUESE.PDF > . Acesso em: 29 ago. 2021

AVRITZER, Leonardo. O pêndulo da democracia. São Paulo: Todavia, 2019,

BOHOSLAVSKY, Juan Pablo, "Covid-19, economia e direitos humanos", SUR 30 - v.17 n.30, 2020, p. $85-99$

BRASIL. Tribunal Superior Eleitoral. O CAMINHO DA PROSPERIDADE: Proposta de Plano de Governo. Disponível em <https://divulgacandcontas.tse.jus.br/candidaturas/oficial/2018/BR/BR/2022802018/2800006 14517/proposta_1534284632231.pdf>. Acesso em 29 ago. 2021.

MOREIRA, Marcelo Sevaybricker. DEMOCRACIAS NO SÉCULO XXI: CAUSAS, SINTOMAS E ESTRATÉGIAS PARA SUPERAR SUA CRISE. Lua Nova, São Paulo , n. 111, p. 15-49, dez. 2020.

O’DONNELL, Guillermo. Poliarquias e a (in) efetividade da lei na América Latina. Novos Estudos CEBRAP, v. 51, p. 37-61, 1998.

SANTOS, Wanderley Guilherme. A democracia impedida: o Brasil no século XXI. Rio de Janeiro: FGV, 2017,

SILVA, Diogo Bacha; BAHIA, Alexandre Gustavo Melo Franco Moraes. Direito à saúde, jurisdição constitucional e estado de emergência constitucional: uma perspectiva crítica da pandemia. Revista Direito e Práxis, v. 12, p. 830-860, 2021.

STREECK, Wolfgang. Tempo comprado: a crise adiada do capitalismo democrático. São Paulo: Boitempo, 2018.

TILLY, Charles. Democracia. Petrópolis: Vozes, 2013. 
TRIVISONNO, Alexandre Travessoni Gomes; RODRIGUES, Gabriel Costa Val. O conceito de direitos humanos: ortodoxo ou político?. Espaço Jurídico: Journal of Law, v. 19, n. 3, p. 703-730, 2018.

TUSHNET, Mark. Constitutional hardball. John Marshall Law Review, v. 37, p. 523, 2003.

VENTURA, Deisy de Freitas Lima; BUENO, Flávia Thedim Costa. De líder a paria de la salud global: Brasil como laboratorio del "neoliberalismo epidemiológico" ante la Covid-19. Foro Internacional, p. 427-467, 2021.

VIEIRA, Oscar Vilhena; GLEZER, R. E. Populismo autocrático e resiliência Constitucional. INTERESSE NACIONAL v. 47, p. 66-76, 2019. 